\title{
Polycystic kidney disease gene in the Lewis polycystic kidney rat is mapped to chromosome I0q2I-q26
}

\author{
Jada Pasquale Yengkopiong \\ Dr John Garang Memorial University \\ of Science and Technology, Faculty of \\ Science and Technology, Bor, \\ Republic of South Sudan
}

This article was published in the following Dove Press journal:

Advances in Genomics and Genetics

9 August 2012

Number of times this article has been viewed

Background: Polycystic kidney disease (PKD) is a life-threatening disorder that affects the kidneys of millions of people across the world. The disease is normally inherited, but it can also be acquired, and leads to development of many cysts in the renal nephrons. In this study, the aim was to characterize PKD in the Lewis polycystic kidney (LPK) rat, the newest model for human PKD.

Methods: Mating experiments were performed between male LPK rats with PKD and female Brown Norway and Wistar Kyoto rats without PKD to raise second filial (F2) and backcross 1 (BC1) progeny, respectively. Rats that developed PKD were identified. Histological examination of the kidneys and liver was performed. Liver tissue samples were collected from each rat and used to extract DNA. The extracted DNA was amplified, and mapping and linkage analyses were performed to identify the quantitative trait locus that controlled the disease phenotypes. Results: It was established that the disease was controlled by a recessive mutation in a single gene $\left(\mathrm{F} 2: \mathrm{PKD}=42\right.$, non-PKD $=110, \chi^{2}=0.53 ; \mathrm{BC} 1: \mathrm{PKD}=67$, non-PKD $=72, \chi^{2}=0.18$, $P>0.05)$ and that the disease was inherited as autosomal recessive polycystic kidney disease (ARPKD). The rats with PKD developed larger fluid-filled cystic kidneys, higher systolic blood pressure, and anemia. However, there were no extrarenal cysts and no pup deaths. Mapping studies and linkage analyses associated the disease phenotypes in both the $\mathrm{F} 2$ and $\mathrm{BC} 1$ rats to chromosome 10q21-q26, giving a maximum LOD score of $7.9(P=0.00001)$ between peak markers D10Rat180 and D10Rat26.

Conclusion: The quantitative trait locus on chromosome 10q21-q26 does not contain the $P k h d-1$ gene, and it is different from quantitative trait loci that control ARPKD in other murine models. The candidate genes located in the quantitative trait locus are important in signal transduction, cell growth, cell proliferation, and cell differentiation. Although expression of PKD in the LPK rat shares common phenotypic traits with ARPKD caused by mutation in Pkhd-1, the gene responsible for ARPKD in the LPK rat is different and unknown, or a mechanism yet to be identified is responsible for development of the disease.

Keywords: polycystic kidney disease, quantitative trait locus, signal transduction, cell proliferation

\section{Introduction}

Polycystic kidney disease (PKD) is a group of heterogeneous, genetically inherited human renal disorders that affects millions of people all over the world. ${ }^{1,2}$ The disease leads to development of numerous fluid-filled cysts in the kidneys. Extrarenal cysts in the liver, pancreas, blood vessels, spleen, testes, and ovaries are common in humans and animals that develop PKD. ${ }^{1,3}$ Furthermore, research has shown that dysfunction of genetic loci in different chromosomes in different animal species is associated 
with the development of PKD. ${ }^{3-5}$ In some cases, the disease is a result of multiple mutations in the same gene. ${ }^{6}$ Based on the genetic expression of PKD, it was found that genetic modifier loci, somewhere along the chromosomes, influenced the development and progression of the disease in different animal species. ${ }^{5,7-9}$

Genetic analyses established that PKD is inherited either as an autosomal recessive (ARPKD) or autosomal dominant (ADPKD) disease. ${ }^{1,10}$ In human studies, the incidence of ADPKD is estimated at one per 500-1000 live births, ${ }^{11,12}$ while that of ARPKD is one per 2000-14,000 live births. ${ }^{13}$ ARPKD is caused by multiple mutations in PKHD- $1^{14,15}$ located on human chromosome 6p21.1-p12. ${ }^{16}$ The PKHD-1 gene consists of 86 exons, assembled into alternative spliced transcripts, and the longest transcript consists of 67 exons, which encodes for fibrocystin/polyductin. ${ }^{17-19}$

ADPKD is a result of mutations in two genes, $P K D-1$, which accounts for $85 \%$ of cases and $P K D-2$, which accounts for $10 \%-15 \%$ of the cases. ${ }^{20}$ The $P K D-1$ gene encodes for polycystin-1 and $P K D-2$ encodes for polycystin- $2 .{ }^{21}$ A small percentage of patients with $\mathrm{PKD}$, which is not associated with mutation in $P K D-1$ or $P K D-2$ genes, has been identified and the gene is now called $P K D-3 .{ }^{22}$ However, this gene is not mapped to any chromosome. In addition to PKD, which leads to development of cysts in the kidneys, there is also nephronophthisis with phenotypes that resemble the PKD phenotypes. However, this disease is a result of mutations in at least eight genes which are different from the $P K D$ genes. $^{23}$

ARPKD is an infantile disease, ${ }^{24}$ ADPKD has an adult onset, ${ }^{25}$ while nephronophthisis may be inherited as a dominant or recessive trait. ${ }^{23}$ These diseases lead to development of extrarenal cysts, high systolic blood pressure, anemia, and eventually renal failure. ${ }^{16,18,26}$ In all cases of $\mathrm{PKD}$, congestive heart failure is a feature that cannot be avoided. ${ }^{27,28}$

To the present, many murine models have been identified and used to study and understand the development and progression of PKD. ${ }^{10,14,29}$ However, the polycystic kidney (PCK) rat model seems to present with PKD phenotypes that resemble human PKD phenotypes. ${ }^{30,31}$ In the current study, PKD in the Lewis polycystic kidney (LPK) rat, the newest model, is characterized. This model arose from the Lewis ( $\mathrm{LEW} / \mathrm{SsNArc}^{-/-}$) strain that spontaneously developed enlarged cystic kidneys at the Animal Resources Center of Western Australia in 2003. Mating experiments between brothers and sisters with enlarged cystic kidneys produced $100 \%$ progeny with bilaterally enlarged fluid-filled cystic kidneys. ${ }^{32}$ However, there were no extrarenal cysts and the disease did not lead to any pup deaths. This colony is now called the Lewis polycystic kidney $\left(\mathrm{LPK} / \mathrm{SsNArc}^{+/+}\right)$rat. However, it was not clear whether the disease was inherited as a recessive or dominant trait. Equally, it was not known which chromosome or locus within the chromosome carried the mutated gene responsible for the disease phenotypes. Furthermore, it was not clear how many genes or mutations were involved in development of the disease.

\section{Materials and methods Mating experiments}

Mating experiments were performed between mutant LPK/ $\mathrm{SsNArc}^{+/+}$male rats and nonmutant Brown Norway (BN/ $\mathrm{ssArc}^{--}$) and Wistar Kyoto (WKY/NArc ${ }^{--}$) female rats to raise second filial (F2) and backcross 1 (BC1) progeny, respectively. The Brown Norway and Wistar Kyoto rat strains are genetically distant from the LPK rat strain. Both strains were used in the study to understand the effect of genetic background of the two female rat strains on the phenotypic expression of PKD. The experiments were performed according to the guidelines of the animal ethic committees of Murdoch University and the Animal Resources Center of Western Australia.

\section{Phenotypic trait analysis}

The progeny were earmarked and recorded. They were palpated once a week from immediately after birth until euthanasia to determine which rats had enlarged kidneys. Enlarged kidneys were confirmed on euthanasia and the presence of cysts was established on histological examination of the kidneys. Systolic blood pressure was measured when the rats were 12 weeks old by the tail-cuff method using the NIBP controller (ADI Instruments, Castle Hill, NSW, Australia). At least three measurements were taken, and the average measurement was used in statistical analysis. Urine was collected from the $\mathrm{BC} 1$ progeny using metabolic cages and its chemistry was determined.

\section{Euthanasia}

Euthanasia of the rats was carried out using a carbon dioxide and oxygen gas mixture, in proportions of 80:20, respectively. After euthanasia, the rats were weighed and the mass recorded in grams. Blood was removed by cardiac puncture into lithium-heparin tubes. The rats were opened on the ventral side along the linear alba and kidneys, and sections of liver were removed. Each kidney was weighed, the mass was recorded, and the kidneys and sections of liver 
were fixed in $4 \%$ formaldehyde solution. Sections of the liver and tail tips were stored at $-80^{\circ} \mathrm{C}$ for DNA extraction.

\section{Packed cell volume}

The packed cell volume was determined in $2 \mathrm{~mL}$ of blood at the Department of Pathology, Murdoch University, with a microhematocrit technique, using an Haeraeus Biofuge hemocentrifuge, according to the manufacturers' instructions (Randox Laboratories Ltd, Crumlin, UK).

\section{Blood chemistry}

Plasma total solid protein was estimated on ethylenediamine tetra-acetic acid using a refractometer according to the manufacturer's instructions (Randox Laboratories Ltd). Plasma creatinine was determined in the same way as for urine creatinine, except that no dilution of samples was carried out. Plasma urea was measured on the Randox Daytona, with the reaction catalyzed by urease enzyme (Randox Laboratories Ltd). The ammonia produced during the reaction combined with $\alpha$-oxoglutarate and hydrogenated nicotinamide adenine dinucleotide (NADH), in the presence of glutamate-dehydrogenase, to yield glutamate and NAD ${ }^{+}$. The $\mathrm{NAD}^{+}$produced was measured in $\mu \mathrm{mol} / \mathrm{L}$ using an ultraviolet method.

\section{Urine chemistry}

Urine was collected from each $\mathrm{BC} 1$ rat between $10 \mathrm{am}$ and 4 pm using metabolic cages. To $20 \mu \mathrm{L}$ of urine samples, blank and standard solution, $1000 \mu \mathrm{L}$ of Pyrogallol red was added. This was mixed and incubated at $37^{\circ} \mathrm{C}$ for 5 minutes. The absorbance of the samples $\left(\mathrm{A}_{\text {sample }}\right)$ and the standard $\left(\mathrm{A}_{\text {standard }}\right)$ was measured against the reagent blank at $600 \mathrm{~nm}$ using a spectrophotometer. Protein concentration was calculated according to the instructions of the manufacturers (Randox Laboratories Ltd):

$$
\text { Protein concentration }(\mathrm{g} / \mathrm{L})=\mathrm{A}_{\text {sample }} \times[\text { standard }] / \mathrm{A}_{\text {standard }}
$$

where [standard] is the concentration of the standard solution in $\mathrm{g} / \mathrm{L}, \mathrm{A}_{\text {sample }}$ is the absorbance of the sample, and $\mathrm{A}_{\text {standard }}$ is the absorbance of the standard solution.

Urine creatinine was determined by the following procedure. To $20 \mu \mathrm{L}$ of urine sample (diluted 1 in 20 with distilled water) was added sodium hydroxide and picric acid, as per the instructions provided by the manufacturers (Randox Instruments). Creatinine, in the presence of sodium hydroxide solution, reacts with picric acid to form a colored complex. The rate of formation of the complex was measured using a colorimetric method. The urine protein/creatinine ratio was calculated according to the instructions of the manufacturer:

Protein $/$ creatinine ratio $=8840[$ protein $] /[$ creatinine $]$

where [protein] is the concentration of protein in $\mathrm{g} / \mathrm{L}$ and [creatinine] is the concentration of creatinine in $\mathrm{g} / \mathrm{L}$.

\section{Histological examination of tissues}

Histological examination of the sections of kidney and liver tissues was carried out at the Department of Histology, Murdoch University. The tissues were paraffin-embedded and sectioned ( $4 \mu \mathrm{m}$ thickness) using a microtome. The sections were fixed on glass slides, stained with hematoxylin and eosin, and viewed under a light microscope and the images were digitalized using a camera (Olympus, Perth WA, Australia).

\section{Genetic analysis Simple sequence repeat markers}

The simple sequence repeat markers used for the mapping studies were chosen from the rat genome database (http:// rgd.mcw.edu/). One simple sequence repeat marker was taken from the extreme ends of each chromosome and two or more markers between. In total, 150 simple sequence repeat markers distributed across the 20 rat autosomes were screened in the study, but only 96 were found to be informative, and therefore used in the mapping studies. The simple sequence repeat markers used in the study to map chromosomes 1 to 20 are shown in Table 1.

\section{DNA extraction and PCR analysis}

The extraction of DNA from liver tissue was carried out according to the instructions provided in the Standard Tissue Kit Protocol ${ }^{\circledR}$ (QIAamp DNA Mini Kit, Qiagen, Valencia, CA). The DNA was quantified using a NanoDrop ${ }^{\circledR}$, ND-1000 (Biolab Inc, Lawrenceville, GA).

The polymerase chain reaction (PCR) was performed in a total volume of $10 \mu \mathrm{L}$ containing $10 \%(\mathrm{w} / \mathrm{v})$ Cresol Red solution; PCR buffer [6.7 mM Tris- $\mathrm{HCl}$, pH 8.8, $1.66 \mathrm{mM}$ $\left(\mathrm{NH}_{4}\right)_{2} \mathrm{SO}_{4}, 0.045 \%$ Triton $\mathrm{X}-100,0.02 \mathrm{mg} / \mathrm{mL}$ gelatin]; $0.25 \mathrm{mM}$ of total dNTPs; $10 \mathrm{pM}$ each of forward and reverse primers; $1 \mathrm{U}$ Taq polymerase; $1.5 \mathrm{mM} \mathrm{MgCl}_{2}$, and $20 \mathrm{ng} / \mu \mathrm{L}$ genomic DNA template in the reaction mixture. The amplification of DNA was performed using touchdown conditions, with an initial denaturation temperature of $94^{\circ} \mathrm{C}$ for 3 minutes, followed by 8 cycles at $94^{\circ} \mathrm{C}$ for 30 seconds, $63^{\circ} \mathrm{C}$ for 30 seconds and $72^{\circ} \mathrm{C}$ for 30 seconds, and the temperature decreased to $55^{\circ} \mathrm{C}$, one cycle $/ 1^{\circ} \mathrm{C}$. A further 30 cycles 
Table I Simple sequence repeat markers used to map the 20 rat autosomes, rat genome database identity, the chromosomes and their total length in $\mathrm{CM}$, the name of the marker, the motif of the markers, the distance of each marker from the top of the chromosome in CM, the predicted fragment size in base pairs for each marker, and the start and stop position of each marker in the chromosomes

\begin{tabular}{|c|c|c|c|c|c|c|c|c|}
\hline ID & Chr & Length (cM) & Name & Motif & $\mathbf{c M}$ & Size & Start & Stop \\
\hline 39666 & 1 & 149.25 & DIRat246 & $(\mathrm{CA}) \mathrm{n}$ & 0.04 & 227 & 2436832 & 2437062 \\
\hline 40798 & 1 & & DIRat256 & $(\mathrm{GT}) \mathrm{n}$ & 28.34 & 207 & 53871755 & 53872145 \\
\hline 37930 & I & & DIRatl83 & (GT)n & 65.46 & 226 & $|3||23| 8 \mid$ & $|3||2354|$ \\
\hline 39264 & I & & DIRatI94 & (GT)n & 134.6 & 124 & 246528823 & 246528943 \\
\hline 36896 & 2 & 112.4798 & D2Rat9 & $(C A) n$ & $12.7 \mid$ & 130 & $3349586 I$ & 33496242 \\
\hline 38266 & 2 & & D2Rat I 36 & $(C A) n$ & 43.34 & 215 & 121385356 & 121385565 \\
\hline 40898 & 2 & & D2Rat228 & $(\mathrm{GT}) \mathrm{n}$ & 70.05 & 134 & 181071573 & 181071715 \\
\hline 35340 & 2 & & D2Rat70 & (GT)n & 112.5 & 172 & 254933191 & 254933362 \\
\hline 35981 & 3 & 94.2199 & D3Rat56 & $(\mathrm{GT}) \mathrm{n}$ & 2.47 & 180 & 3577905 & 3578102 \\
\hline 41476 & 3 & & D3Rat 193 & $(\mathrm{CA}) \mathrm{n}$ & 3.49 & 147 & 10016016 & 10016172 \\
\hline 40968 & 3 & & D3Rat 194 & (GT)n & 3.53 & 199 & 10311363 & 10311552 \\
\hline 42639 & 3 & & D3Rat23I & (GT)n & 3.57 & 224 & 9925540 & 992575 I \\
\hline 40854 & 3 & & D3Rat 192 & (GT)n & 4.62 & 235 & 12470687 & 12470922 \\
\hline 37166 & 3 & & D3Ratl I0 & $(\mathrm{CA}) \mathrm{n}$ & 32.82 & 121 & 42729639 & 42729760 \\
\hline 38316 & 3 & & D3Rat68 & $(C A) n$ & 76.61 & 199 & 153994739 & 153995233 \\
\hline 38244 & 3 & & D3Rat I 32 & $(\mathrm{CA}) \mathrm{n}$ & 91.49 & 208 & 165064454 & 165064659 \\
\hline 36305 & 4 & 102.2399 & D4Rat4 & $(\mathrm{CA}) \mathrm{n}$ & 0.04 & 182 & 3237190 & 3237361 \\
\hline 41182 & 4 & & D4Rat I 68 & $(\mathrm{CA}) \mathrm{n}$ & $37.4 I$ & 142 & 77155286 & 77155422 \\
\hline 40642 & 4 & & D4Rat I 95 & (GT)n & 65.69 & 215 & $|43875| \mid 5$ & | 43875322 \\
\hline 38580 & 4 & & D4Rat I 40 & (GA)n & 98.81 & 146 & 182740817 & $18274 \mid 162$ \\
\hline 40250 & 5 & 105.6599 & D5Rat I 25 & (GT)n & 9.22 & 234 & | $770296 \mid$ & 17703194 \\
\hline 38548 & 5 & & D5Rat82 & $(\mathrm{CA}) \mathrm{n}$ & 26.04 & 240 & 45822600 & 45822846 \\
\hline 39248 & 5 & & D5Rat72 & $(\mathrm{CA}) \mathrm{n}$ & 63.77 & 226 & 120983238 & I20983466 \\
\hline 38574 & 5 & & D5RatlII & $(C A) n$ & 103.9 & 225 & 30418090 & 30418319 \\
\hline 35963 & 6 & 85.1598 & D6Rat46 & (GT)n & 1.15 & 144 & 13286615 & I3286759 \\
\hline 39972 & 6 & & D6Rat I 32 & (GT)n & 39.81 & 221 & 52753065 & 52753434 \\
\hline 37376 & 6 & & D6Rat87 & (GT)n & 56.75 & 173 & 98742972 & 98743161 \\
\hline 39052 & 6 & & D6RatI0I & $(C A) n$ & 81.77 & 120 & 135964407 & 135964844 \\
\hline 35382 & 7 & 88.5699 & D7Rat36 & $(C A) n$ & 0.04 & 180 & 1526177 & I526344 \\
\hline 35237 & 7 & & D7Rat35 & (GT)n & 3.9 & 125 & 20307479 & 20307622 \\
\hline 38322 & 7 & & D7Rat63 & $(\mathrm{CA}) \mathrm{n}$ & 4.6 & 246 & | 4454482 & | $445483 \mid$ \\
\hline 35068 & 7 & & D7Rat32 & $(\mathrm{CA}) \mathrm{n}$ & 11.42 & 143 & 21790655 & 21790795 \\
\hline 40050 & 7 & & D7Ratl 52 & (GT)n & 17.91 & $|3|$ & 25926004 & 25926410 \\
\hline 39016 & 7 & & D7RatI03 & $(C A) n$ & 25.4 & 200 & 44462790 & 44463229 \\
\hline 36932 & 7 & & D7Rat I7 & $(C A) n$ & 57.96 & 135 & 100258077 & 100258647 \\
\hline 36193 & 7 & & D7Rat3 & (GT)n & 86.23 & 128 & |3740438| & I 37404493 \\
\hline 36039 & 8 & 85.2699 & D8Rat58 & $(\mathrm{CA}) \mathrm{n}$ & 0 & 174 & 3039648 & 3039822 \\
\hline 38690 & 8 & & D8Rat98 & (GT)n & 38.06 & 214 & 53665152 & 53665540 \\
\hline 41310 & 8 & & D8Rat I 30 & $(\mathrm{CA}) \mathrm{n}$ & 57.27 & 174 & 98986085 & 98986263 \\
\hline 37976 & 8 & & D8Rat69 & $(C A) n$ & 83.04 & 148 & 125922482 & 125922636 \\
\hline 35695 & 9 & 79.5198 & D9Rat44 & $(\mathrm{CA}) \mathrm{n}$ & 1.33 & 176 & 2948882 & 2949051 \\
\hline 37416 & 9 & & D9Rat70 & (GT)n & 23.24 & 190 & 21667066 & 21667255 \\
\hline 41600 & 9 & & D9Rat II0 & $(C A) n$ & 64.74 & 174 & 94217517 & 94217673 \\
\hline 37268 & 9 & & D9Rat75 & $(C A) n$ & 76.1 & 212 & 104531509 & $|0453| 80 \mid$ \\
\hline 37464 & 10 & 95.4399 & DIORat95 & (GT)n & 0.04 & 217 & 6380753 & 6381051 \\
\hline 41524 & 10 & & DIORat2I8 & $(C A) n$ & 4.5 & 143 & 9092033 & 9092176 \\
\hline 38756 & 10 & & DIORat 180 & $(C A) n$ & 4.6 & 170 & 19148316 & 19148638 \\
\hline 35001 & 10 & & DI0Rat43 & (TG)n & 24.27 & 150 & $23428 \mid 27$ & 23428280 \\
\hline 36319 & 10 & & DIORat26 & (TG)n & 51.03 & 167 & 72105962 & 72106120 \\
\hline 35627 & 10 & & DIORatI2 & (TG)n & 76.13 & 170 & 99198838 & 99198997 \\
\hline $3494 I$ & 10 & & DI0Rat7 & $(C A) n$ & 87 & 173 & $|0588624|$ & $1058864 \mid 4$ \\
\hline 35665 & 10 & & DIORat4 & (GT)n & 95.44 & 164 & 107033560 & 107033716 \\
\hline 37070 & 11 & 41.6299 & DIIRat28 & (GT)n & 2.55 & 246 & 13185810 & 13186049 \\
\hline 39084 & 11 & & DIIRat93 & $(C A) n$ & 29.84 & 240 & 67930910 & 67931151 \\
\hline 40938 & 11 & & DIIRat56 & (GT)n & 35.73 & 195 & 77880883 & 77881082 \\
\hline
\end{tabular}


Table I (Continued)

\begin{tabular}{|c|c|c|c|c|c|c|c|c|}
\hline ID & Chr & Length (cM) & Name & Motif & $\mathbf{c M}$ & Size & Start & Stop \\
\hline 38800 & II & & DIIRat43 & $(\mathrm{GT}) \mathrm{n}$ & 41.63 & 234 & 85039892 & 85040103 \\
\hline 40394 & 12 & 54.0099 & DI2Rat89 & $(\mathrm{GT}) \mathrm{n}$ & 2.13 & 139 & 2957061 & 2957210 \\
\hline 37272 & 12 & & DI2Rat28 & (GT)n & 20.46 & 120 & 16312645 & $|63| 277 \mid$ \\
\hline 37830 & 12 & & DI2Rat36 & $(G T) n$ & 42.14 & 200 & 33216127 & 33216334 \\
\hline 38410 & 12 & & DI2Rat53 & (GT)n & 51.79 & 134 & 43863148 & 43863270 \\
\hline 40188 & 13 & 44.1698 & DI3Rat I08 & $(C A) n$ & 0.29 & 219 & 21828843 & 21829056 \\
\hline 38990 & 13 & & DI3Rat58 & $(\mathrm{GT}) \mathrm{n}$ & 26.04 & 249 & 71116479 & 71116738 \\
\hline 40656 & 13 & & DI3RatI3I & (GT)n & 33.98 & 147 & 80755428 & 80755583 \\
\hline 39262 & 13 & & DI3Rat86 & $(C A) n$ & 40.75 & 209 & 91410706 & 91411049 \\
\hline 36890 & 14 & 712399 & DI4Rat2 & (GT)n & 0 & 160 & 2350091 & 2350247 \\
\hline 40852 & 14 & & DI4Rat90 & $(C A) n$ & 34.67 & III & 73956596 & 7395670I \\
\hline 41138 & 14 & & DI4Rat94 & (GT)n & 49.47 & 235 & 89192602 & 89192873 \\
\hline 39030 & 14 & & DI4Rat38 & $(\mathrm{GT}) \mathrm{n}$ & 63.96 & 200 & $990798 \mid 4$ & 99080020 \\
\hline 36516 & 15 & 66.5498 & DI5Rat I & $(G T) n$ & 1.63 & 280 & 8988164 & 8988442 \\
\hline 36189 & 15 & & DI5RatI7 & (GT)n & 33.51 & 178 & 45042674 & 45042874 \\
\hline 40252 & 15 & & DI5RatI0I & (GT)n & 53.95 & 157 & 38968338 & 38968494 \\
\hline 41308 & 15 & & DI5Ratl07 & $(C A) n$ & 65.4 & $|5|$ & 55591156 & 55591299 \\
\hline 40498 & 16 & 45.5099 & DI6Rat I07 & $(G T) n$ & 2.32 & 133 & 7776021 & 7776427 \\
\hline 38428 & 16 & & DI6Rat53 & (GT)n & 28.33 & 133 & 66606252 & 66606369 \\
\hline 39010 & 16 & & DI6Rat34 & $(\mathrm{GT}) \mathrm{n}$ & 33.98 & 238 & 72653395 & 72653827 \\
\hline 36608 & 16 & & DI6Rat48 & $(\mathrm{CA}) \mathrm{n}$ & 45.51 & 150 & 79850041 & 79850195 \\
\hline 36051 & 17 & 47.5999 & DI7RatI & $(C A) n$ & 3.67 & 166 & 5583326 & 5583494 \\
\hline 36011 & 17 & & DI7RatI7 & $(\mathrm{GACA}) \mathrm{n}$ & 28.16 & 168 & 42344830 & 42344987 \\
\hline 37998 & 17 & & DI7Rat96 & $(G T) n$ & 37.14 & 205 & 78253719 & 7825407I \\
\hline 41084 & 17 & & DI7Rat|3I & $(C A) n$ & 47.54 & 201 & 93347783 & 93347990 \\
\hline 41120 & 18 & 52.3799 & DI8RatII2 & $(\mathrm{GT}) \mathrm{n}$ & 2.48 & 223 & 6489051 & 6489519 \\
\hline 39444 & 18 & & DI8Rat96 & (GT.GA)n & 16 & 247 & $4 \mid 105037$ & 41105280 \\
\hline 34975 & 18 & & DI8RatI3 & (TTTC)n & 38.79 & 149 & 61728726 & 61728877 \\
\hline 39278 & 18 & & DI8Rat44 & $(\mathrm{GT}) \mathrm{n}$ & 52.38 & 210 & 86863206 & $8686341 I$ \\
\hline 37042 & 19 & 48.1398 & DI9RatI9 & (CT)n & 2.24 & 140 & 7813537 & $78|367|$ \\
\hline 35881 & 19 & & DI9RatII & (GT)n & 22.52 & 128 & 31605037 & 31605157 \\
\hline 40110 & 19 & & DI9Rat64 & $(\mathrm{GT}) \mathrm{n}$ & 38.05 & 243 & 46434967 & 46435202 \\
\hline 43138 & 19 & & DI9Rat5 & (GT)n & 46.36 & 157 & 54509577 & 54509737 \\
\hline 37490 & 20 & 48.2299 & D20Rat2I & $(G A) n$ & 0 & 170 & 1674648 & 1675005 \\
\hline 35327 & 20 & & D20Rat I0 & $(\mathrm{GT}) \mathrm{n}$ & 23.96 & 156 & 33642621 & 33642779 \\
\hline 38304 & 20 & & D20Rat I9 & (GT)n & 37.79 & 178 & 45070473 & 45070798 \\
\hline 37792 & 20 & & D20Rat29 & $(C A) n$ & 43.54 & 241 & 48055659 & 48055886 \\
\hline
\end{tabular}

at $94^{\circ} \mathrm{C}$ for 30 seconds, $55^{\circ} \mathrm{C}$ for 30 seconds, and $72^{\circ} \mathrm{C}$ for 30 seconds were carried out. A final extension at $72^{\circ} \mathrm{C}$ for 5 minutes was allowed.

The PCR products were separated using $8 \%$ polyacrylamide (acrylamide/bis-acrylamide solutions $40 \% \mathrm{w} / \mathrm{v}$ ) gel, and electrophoresis was carried out for 20 hours using $1 \times$ Tris-base-boric acid-ethylenediamine tetra-acetic acid buffer. The potential difference for electrophoresis was set at 4 volts/cm and the gels were stained with ethidium bromide solution (E1510, Sigma, St Louis, MO, $10 \mathrm{mg} / \mathrm{mL}$ ). The image of the gel was visualized using ultraviolet light on a transilluminator.

\section{Scoring of genotypes and linkage analyses}

The alleles amplified by each simple sequence repeat marker in all the progeny were independently scored by three people either as the homozygote parent A (lpk/lpk) or the heterozygote parent $\mathrm{H}$ (lpk/wky) in the BC1 (Figure 3) and either as the homozygote parent $\mathrm{A}$, homozygote parent B (bn/bn), or heterozygote parent $\mathrm{H}(\mathrm{lpk} / \mathrm{bn})$ in the F2 progeny (data available on request). When there was no agreement in the score because the alleles were not informative, the fragment was scored as a dash. Linkage analysis between the genotype and the phenotype to identify the quantitative trait locus that controlled the disease phenotypes in the LPK rats was carried out using Map Manager QTX20b software. ${ }^{33}$

A minimum $\log _{10}$ likelihood ratio (LOD) score of 3.6 was used to declare the presence of a quantitative trait locus, ${ }^{34}$ and the additive effect for each quantitative trait locus was calculated..$^{33,35}$ The markers that showed LOD scores $>3$ in 
Table 2 Number of progeny in $\mathrm{F} 2$ and $\mathrm{BCI}$ with PKD and without PKD, and the Chi square statistics

\begin{tabular}{lllllll}
\hline Generation & Progeny & E & O & Ratio & $\chi^{2}$ & P-value \\
\hline F2 & 152 & 38 & 42 & I:03 & 0.53 & $\sim 0.99$ \\
BCI & 139 & 69.5 & 67 & I:01 & 0.18 & $\sim 0.97$ \\
\hline
\end{tabular}

Notes: $\chi^{2}$, Chi square values; O, observed number of rats with PKD; E, expected number of rats with PKD; F2, second filial generation; $\mathrm{BCl}$, backcross I generation. Abbreviation: PKD, polycystic kidney disease.

the $\mathrm{BC} 1$ genotype were used in mapping and linkage analyses of the 152 F2 DNA samples.

\section{Statistical analysis}

Statistical analysis was carried out using the Statistical Package for Social Sciences version 16 (SPSS Inc, Chicago, IL). One-way analysis of variance and multiple comparison tests with post hoc analysis of the combined male and female data sets were carried out, and significance was taken at $P<0.05$, unless otherwise stated.

\section{Results}

Segregation ratios showed the inheritance of a recessive mutation in a single gene (Table 2). The cysts were only found in the kidneys of PKD rats and not in kidneys of non-PKD rats (Figure 1).

The blood and urine chemistry showed that the presence of cysts in the kidneys led to deterioration in kidney function. Consequently, the kidneys were unable to concentrate urine. Furthermore, the kidneys were unable to regulate

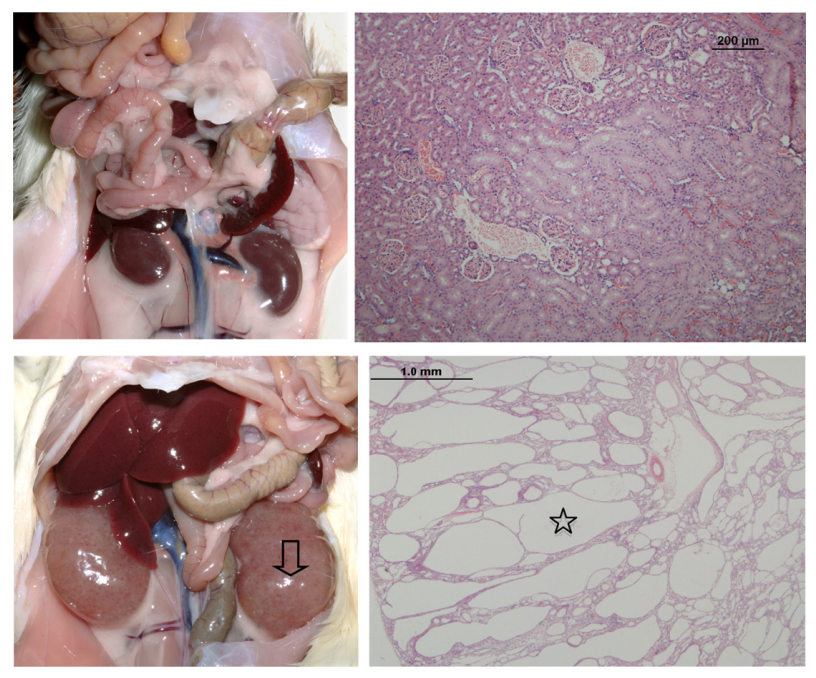

Figure I Gross and microscopic anatomy of kidneys from a $\mathrm{BCl}$ rat that did not develop PKD (above) and gross and microscopic anatomy of kidneys of a $\mathrm{BCl}$ rat that did develop PKD (below).

Notes: The arrow shows the fluid-filled cystic kidney and the star shows the cysts in a cross section of the kidney. Magnification 400x.

Abbreviation: PKD, polycystic kidney disease. the concentration of the osmolytes. An increase in systolic blood pressure (Figure 2A), a decrease in packed cell volume (Figure 2B), and a decrease in urine specific gravity (Figure 2C) strongly suggest that deterioration of kidney function due to development of cysts was responsible for the changes in these phenotypic traits. There was a highly significant difference in the measured clinical parameters between PKD and non-PKD in both male and female rats $(P<0.0001)$. However, there were no significant differences in the measured parameters between male and female rats with or without PKD (Table 3).

In linkage and mapping analyses, the genotypes of $\mathrm{BC} 1$ progeny (Figure 3) and F2 (not shown) associated with a
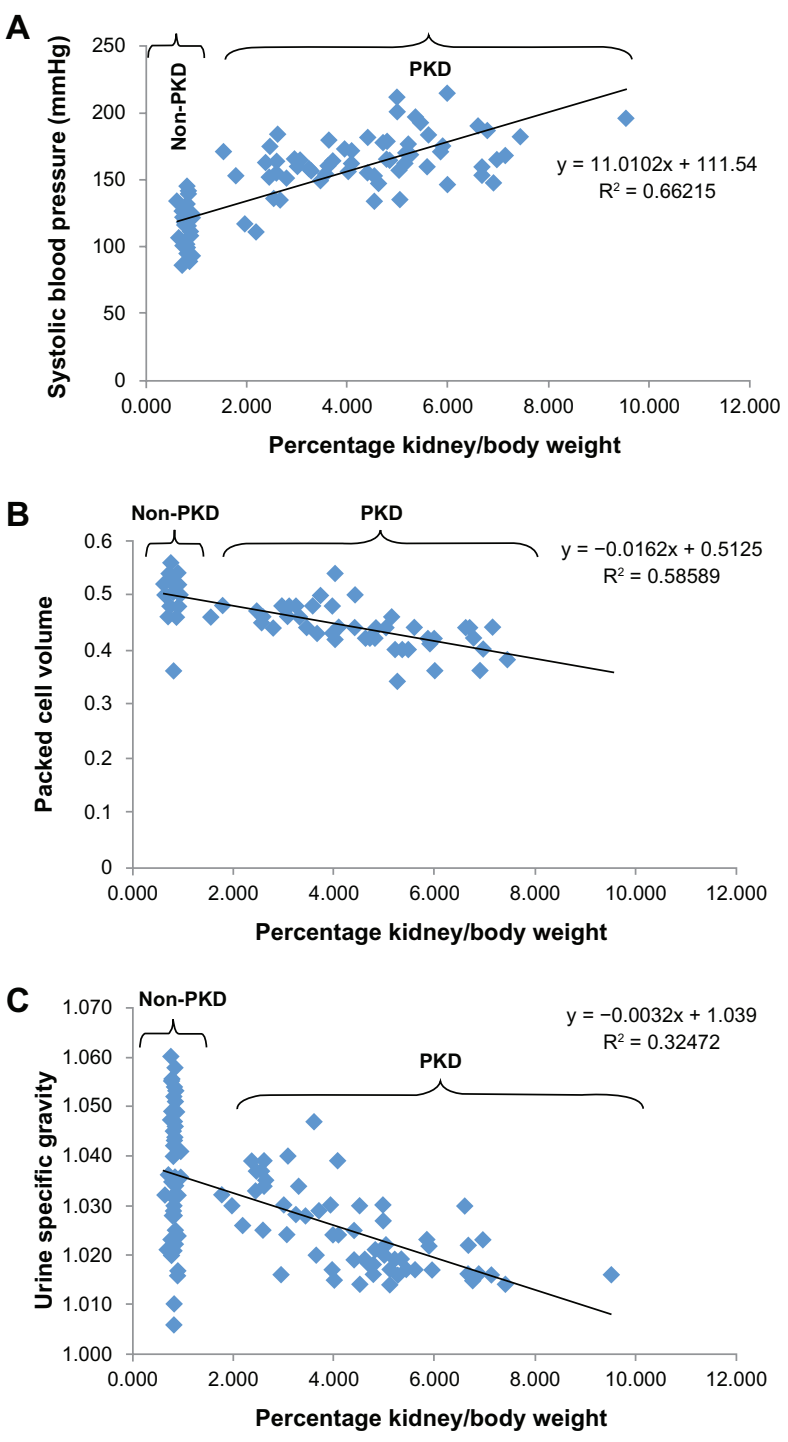

Figure 2 (A) Linear relationship between systolic blood pressure and percentage relative kidney/body weight, $\mathrm{R}^{2}=0.66, P<0.01$. (B) Linear relationship between packed cell volume and percentage kidney/body weight, $R^{2}=0.59, P<0.01$. (C) Linear relationship between urine specific gravity and percentage kidney/body weight, $\mathrm{R}^{2}=0.32, P<0.01$. 
Table 3 Phenotypes for PKD and non-PKD in PKD and non-PKD progeny

\begin{tabular}{|c|c|c|c|c|}
\hline Generation & $\mathbf{N}$ & SBP $(\mathrm{mmHg})^{\mathrm{a}}$ & $\% R K / B W a$ & PCV (L/L) $)^{a}$ \\
\hline \multicolumn{5}{|l|}{ F2 (non-PKD) } \\
\hline Males & 51 & $117.12 \pm 1.45$ & $0.80 \pm 0.03$ & $0.47 \pm 0.01(33)^{\mathrm{b}}$ \\
\hline Females & 58 & $116.29 \pm 1.81$ & $0.79 \pm 0.01$ & $0.48 \pm 0.00(36)^{\mathrm{b}}$ \\
\hline \multicolumn{5}{|l|}{ F2 (PKD) } \\
\hline Males & 17 & $167.35 \pm 5.65^{* * *}$ & $3.99 \pm 0.50 * * * *$ & $0.43 \pm 0.02(\mathrm{I} 4)^{\mathrm{b}, * * * *}$ \\
\hline Females & 26 & $155.46 \pm 3.74 * * *$ & $3.15 \pm 0.37 * * *$ & $0.45 \pm 0.0 \mathrm{I}(\mathrm{I} 7)^{\mathrm{b}, * * *}$ \\
\hline \multicolumn{5}{|c|}{ BCI (non-PKD) } \\
\hline Males & 38 & $118.76 \pm 2.22$ & $0.87 \pm 0.04$ & $0.50 \pm 0.01(26)^{b}$ \\
\hline Females & 38 & || $4.7 \mid \pm 1.74$ & $0.82 \pm 0.03$ & $0.50 \pm 0.00(29)^{\mathrm{b}}$ \\
\hline \multicolumn{5}{|l|}{$\mathrm{BCl}$ (PKD) } \\
\hline Males & 28 & $165.00 \pm 3.28^{* * *}$ & $4.54 \pm 0.30 * * *$ & $0.43 \pm 0.0 \mathrm{I}(19)^{\mathrm{b}, * * * *}$ \\
\hline Females & 35 & $168.14 \pm 2.94 * * *$ & $4.53 \pm 0.26 * * *$ & $0.44 \pm 0.0 \mathrm{I}(28)^{\mathrm{b}, * * *}$ \\
\hline
\end{tabular}

Notes: a Data is presented as Mean \pm SEM; ${ }^{b}$ number of rats in each group of PCV phenotype; $* * * P<0.000$ I between PKD and non-PKD in both male and female rats. Abbreviations: SBP, systolic blood pressure in $\mathrm{mmHg}$; \%RK/BW, percentage relative kidney/body weight; PCV, packed cell volume (L/L); PKD, polycystic kidney disease.

quantitative trait locus region on chromosome 10, and this quantitative trait locus maps to rat chromosome 10q21-q26 (Figure 4 for chromosome 10 only). In this figure, the values for the likelihood ratio statistics were found to be significant (8.4), very significant (13.5), or highly significant (21.3) as previously described.$^{33}$ In both the $\mathrm{BC} 1$ and the F2, the phenotypic traits linked to the same quantitative trait locus (Figure 5). In this figure, the phenotypes of the $\mathrm{BC} 1$ progeny link to a large genetic region, flanked by D10Rat180 and D10Rat26. The phenotypes of the F2 progeny link to a small genetic region within the $\mathrm{BC} 1$ genetic region, flanked by D10Rat43 and D10Rat26 $(P<0.00001)$. This finding confirms that the quantitative trait locus in this genetic region is responsible for the disease phenotypes in both the $\mathrm{BC} 1$ and F2 progeny. Presently, genetic mapping and linkage analyses of chromosome 10 using $\mathrm{F} 2$ traits are in progress to identify the actual quantitative trait locus and the gene responsible for the PKD phenotypes. As such, linkage results from the $\mathrm{BC} 1$ progeny only are discussed in this work.

Figure 6 shows a Manhattan plot where the negative $\log _{10}$ of the $P$ values are plotted against the 20 rat autosomes.
All the phenotypic traits are linked to the same quantitative trait locus region. This quantitative trait locus region maps to human chromosome 5q34-q35 and mouse chromosomes $11 \mathrm{C}$ and 18B1 (Figure 7). In mapping and linkage studies, LOD score and likelihood ratio statistics are commonly used and they are directly related. These are interchangeably used to identify an association between genetic regions that harbor sequence variants, which influence complex phenotypic traits under investigation. ${ }^{33,36}$ The quantitative trait locus region maps to different human and mouse chromosomes (Figure 7), and the candidate genes located in the quantitative trait locus region are presented in Table 4.

\section{Discussion}

This study maps the quantitative trait locus associated with PKD traits in LPK rats. The major findings are that the PKD was a result of a recessive mutation in a single gene and the disease was inherited as ARPKD. The genetic locus that controlled the disease phenotypes was mapped to rat chromosome 10q21-q26. Mutation in this locus resulted in development of cysts in the kidneys of homozygous mutant rats. The presence of

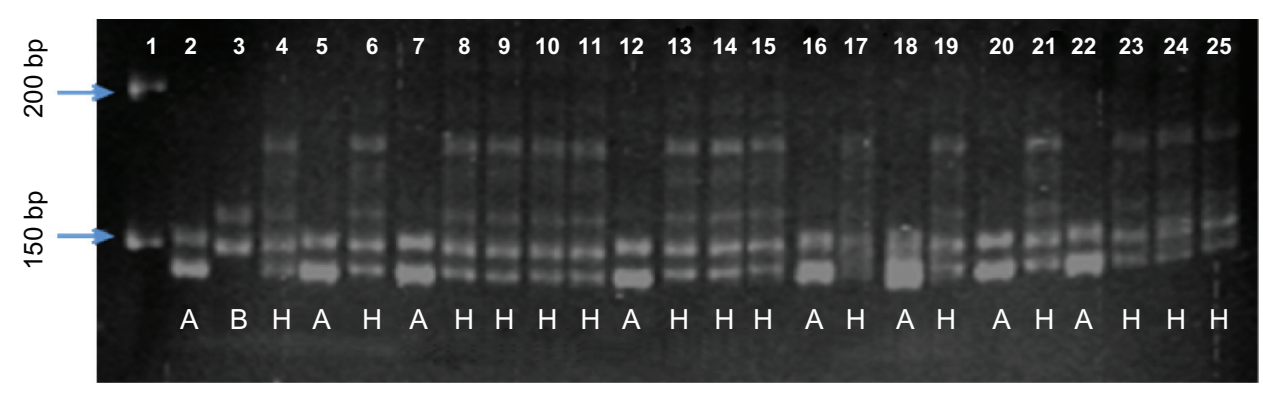

Figure 3 Genotypes for marker DIORat43 in $22 \mathrm{BCI}$ DNA samples.

Notes: Lane I, 50 bp molecular weight marker; lane 2, parent A (LPK/SsNArc ${ }^{+/+}$); lane 3, parent B (WKY/NArc ${ }^{-1-}$ ); lanes 4-25, BCI progeny DNA samples. Parent B is included to show the segregation of alleles in parent $\mathrm{A}$, parent $\mathrm{B}$, and the heterozygote parent, $\mathrm{H}\left(\mathrm{LPK} / \mathrm{SsNArc}^{+/+} / \mathrm{WKY} / \mathrm{NArc}^{-/}\right)$. Parent $\mathrm{H}$ is the female from the $\mathrm{FI}$ progeny. 
cysts in the kidneys led to hypertension, deterioration of kidney functions, development of anemia, and loss of homeostasis by the kidneys in all PKD rats. In this rat model, the inheritance of the disease was not accompanied by development of extrarenal cysts and the disease did not lead to any pup deaths.

It was established that all the F1 progeny $(n=291)$ from the two mating experiments did not develop cystic kidneys. This indicated that a recessive mutation in one gene was involved in the development of the disease, or mutations in several genes that range from dominant to recessive were involved but with interactive effect, making it unlikely that any of the F1 progeny developed the disease, unless a very large number of progeny was studied. The control of PKD phenotype by one gene was confirmed by the ratios of PKD to non-PKD in both the $\mathrm{F} 2$ and the $\mathrm{BC} 1$ progeny $(P>0.05)$.

The phenotypes of PKD in the LPK rats were similar in clinical presentation to the phenotypes of ARPKD in humans. However, there are also some fundamental differences in the two species. In both LPK rats and humans, homozygote individuals present with enlarged fluid-filled cystic kidneys. The cysts develop early in fetal life and in humans, enlarged kidneys can be observed in utero using computed tomography scanning. ${ }^{1}$ In LPK rats, enlarged kidneys were palpated in the first week of birth.

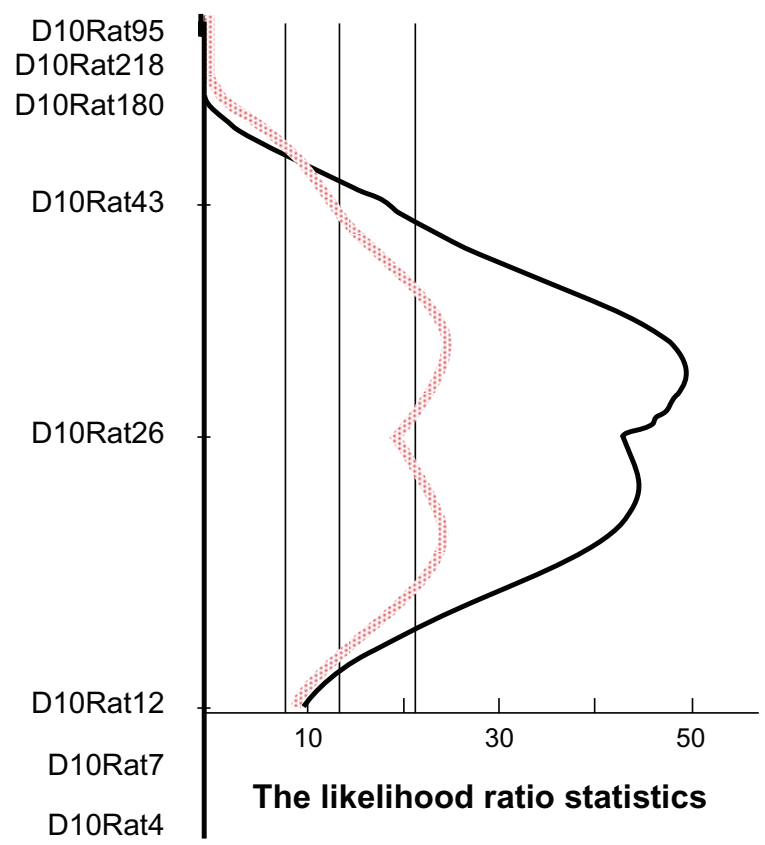

Figure 4 Interval mapping between the PKD phenotype and the $\mathrm{BCl}$ genotypes. Notes: The interval mapping is between the PKD phenotype and the marker genotypes of the BCI DNA samples. The black curved line shows the likelihood ratio statistics and the red curved line is the regression coefficient. The vertical lines (from left to right) show chromosome 10, estimates for critical likelihood ratio statistic values for PKD phenotype: significant (8.4), very significant (I3.5), and highly significant $(21.3, P<0.05)$. Abbreviation: PKD, polycystic kidney disease.
In humans only, infants with ARPKD suffer from pulmonary hyperplasia and most die early in life. ${ }^{37}$ In the LPK rats, there was no case of progeny death. This demonstrates that the progeny did not suffer from pulmonary hyperplasia. Furthermore, in human studies, affected individuals developed extrarenal cysts in the liver, spleen, pancreas, and other extrarenal organs. ${ }^{38}$ However, not all the PKD rats developed extrarenal cysts. The lack of extrarenal cysts in PKD rats may not have been due to the effect of the genetic background of Brown Norway and Wistar Kyoto rats or the effect of modifier loci, as proposed in a study of Wistar polycystic kidney (wpk) rats, ${ }^{37}$ but a result of a mutation in a different gene, which is still unknown. Numerous PKD studies in murine models have shown that genetic modifier loci influence the severity of the disease phenotypes. ${ }^{5,7,9,39} \mathrm{In}$ this study, it is also possible that an unknown mechanism yet to be identified is responsible for development of ARPKD in the LPK rats.

All the PKD rats developed high systolic blood pressure compared with their age-matched counterparts without

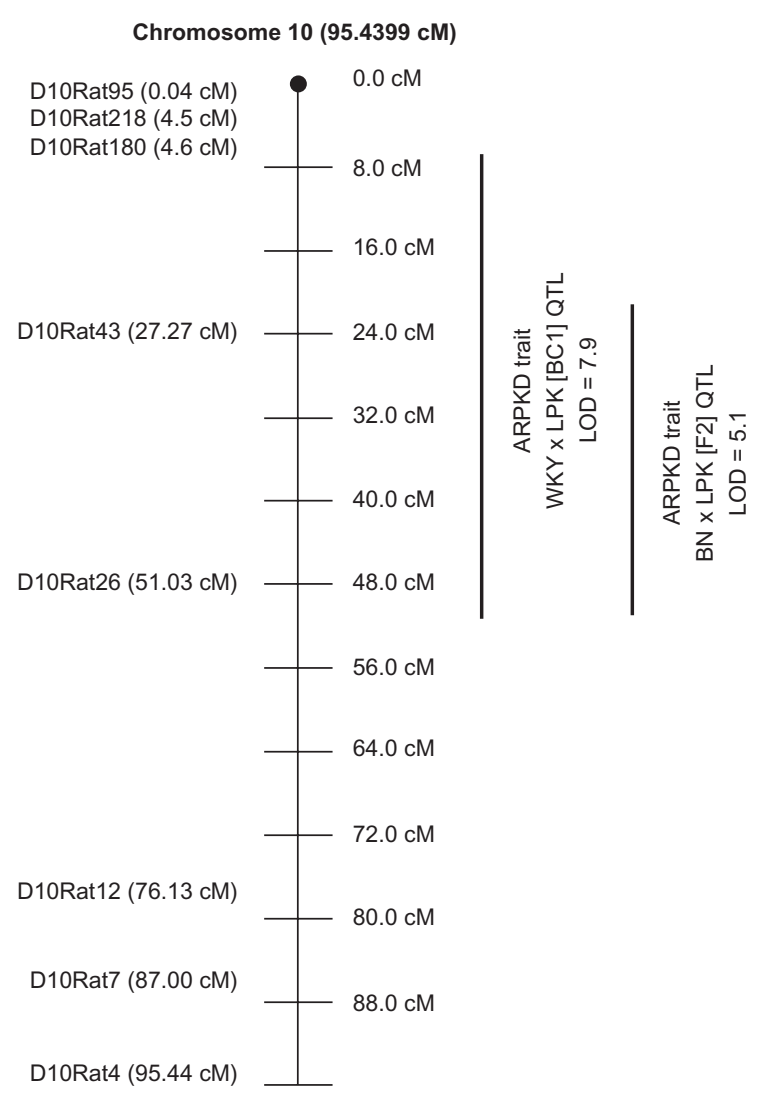

Figure 5 Chromosome 10 and quantitative trait locus containing the locus that controls the PKD phenotypes.

Notes: The quantitative trait loci and LOD scores for $\mathrm{BCl}$ and $\mathrm{F} 2$ progeny. The two peak markers linked to the PKD phenotype in the two crosses are DIORat43 and DIORat26, and they are $23.76 \mathrm{cM}$ apart.

Abbreviation: PKD, polycystic kidney disease. 


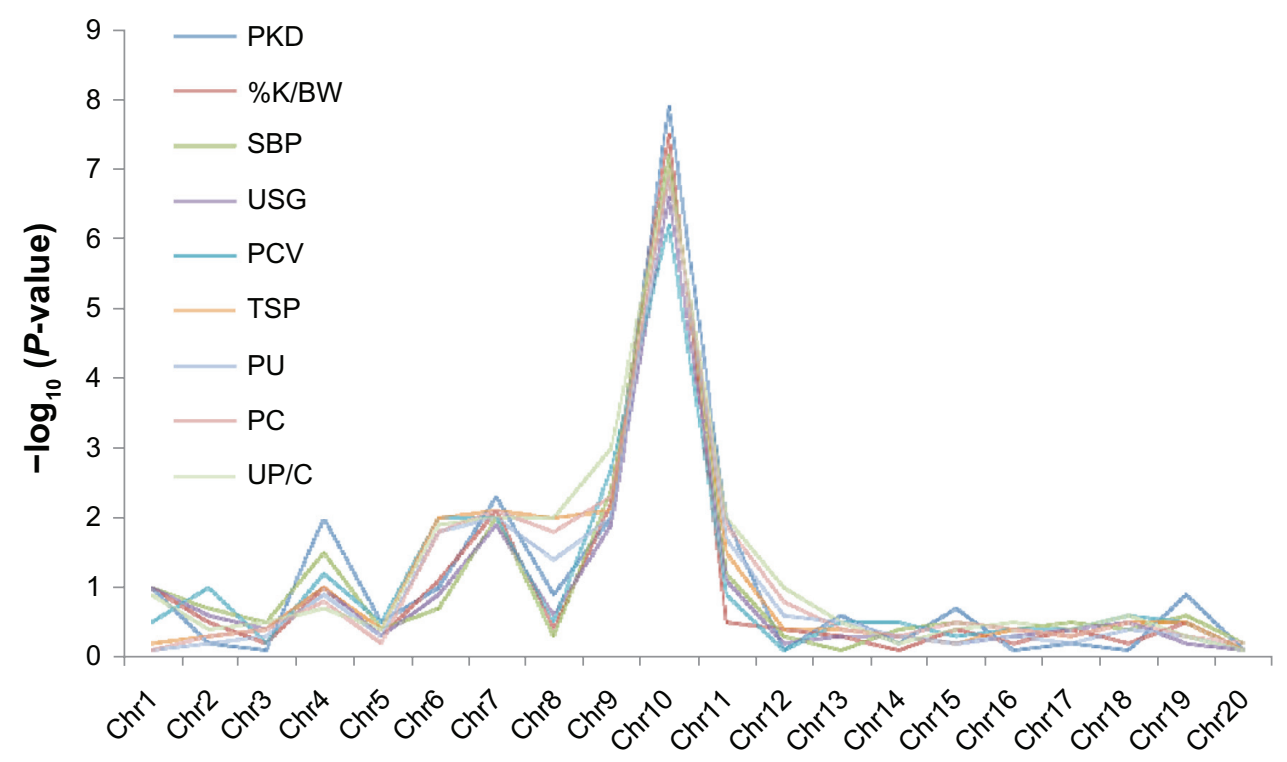

Figure 6 Manhattan plot. Negative $\log _{10}(P$ value $)$ is plotted for each of the 20 rat autosomes.

Notes: All the phenotypic traits link to chromosome $10 q 21-q 26$, shown by the highest peaks. This genetic region is where the recessive mutation in a single gene is located and is responsible for ARPKD in the LPK rats.

Abbreviations: ARPKD, autosomal recessive polycystic kidney disease; LPK, Lewis polycystic kidney.

$\mathrm{PKD}$, and this is a common feature in all PKD patients and animal models. ${ }^{40}$ The development of higher systolic blood pressure in PKD rats preceded end-stage renal disease. This is similar to the development of higher systolic blood pressure in humans with PKD. ${ }^{41}$ However, the mechanism involved in the development of higher systolic blood pressure due to development of PKD in kidneys is not well established in human studies, and is not well understood in LPK rats. However, stimulation of the renin-angiotensin-aldosterone

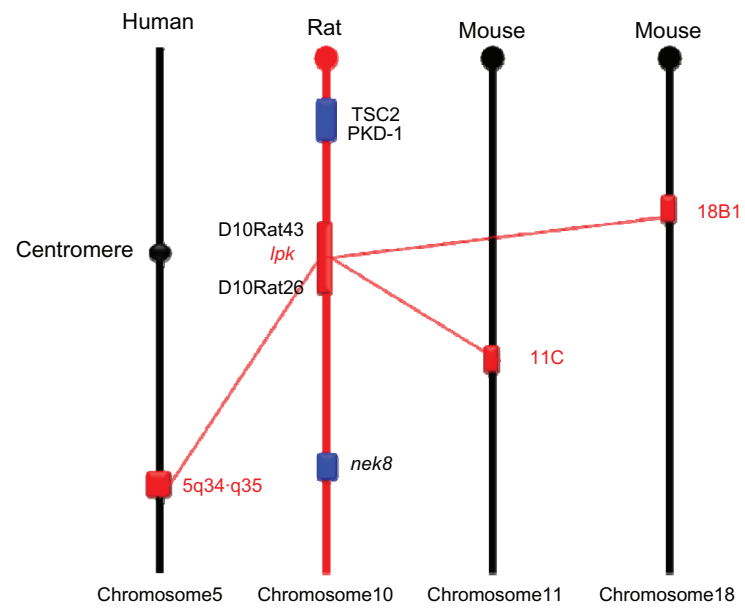

Figure 7 Quantitative trait locus on the LPK rat region 10q2I-q26 mapped to human and mouse chromosomes.

Notes: The quantitative trait locus that controls the phenotype of ARPKD in the $\mathrm{LPK} / \mathrm{SsNArc}{ }^{+/+}$rats maps to human chromosome 5q34-q35 (MAT2 $\beta$ gene) and mouse chromosomes IIC (Bcas3 gene) and I8BI (Rit2 gene).

Abbreviations: ARPKD, autosomal recessive polycystic kidney disease; LPK, Lewis polycystic kidney. system and increased sympathetic activity were suggested to influence systolic blood pressure ${ }^{42,43}$ in all individuals who develop PKD.

Measurement of packed cell volume is important in clinical studies to predict the development of anemia, which results from reduction in red blood cell mass or hemoglobin concentration, or both. ${ }^{44}$ In this study, measurement of packed cell volume was necessary to define the effect of development of renal cysts on kidney function. Decreased packed cell volume in the PKD rats showed that the development of cysts in the kidney affected the physiological and homeostatic functioning of the kidneys.

Mapping and linkage analyses associated the PKD phenotypes in the LPK rats to a quantitative trait locus region on rat chromosome 10q21-q26. Mapping and linkage studies are commonly used to identify quantitative trait loci associated with particular traits. ${ }^{45-48}$ In this study, the same methods were applied to identify the quantitative trait locus responsible for the PKD traits in the LPK rats. It was established that all the phenotypic traits link to the same quantitative trait locus, giving a maximum LOD score of 7.9 between markers D10Rat180 and D10Rat26 in BC1. The LOD score of 5.1 between markers D10Rat43 and D10Rat26 in F2 confirms that this is the actual quantitative trait locus responsible for the disease phenotypes in the LPK rats. The high LOD scores in both $\mathrm{BC} 1$ and $\mathrm{F} 2$ provide strong evidence for linkage between the phenotypic traits and the genotypes located in the quantitative trait locus. ${ }^{33}$ 
Table 4 Candidate genes and proteins encoded by genes in the quantitative trait locus region linked to PKD traits on chromosome $10 q 21-q 26$

\begin{tabular}{lll}
\hline Protein & Gene & Gene ID \\
\hline Methionine adenosyltransferase II & Mat2b & 683630 \\
Kidney injury molecule I & KIMI & 689968 \\
Gamma-aminobutyric acid A receptor gamma 2 & Gabrg2 & 29709 \\
Pituitary tumor-transforming I & PttgI & 64193 \\
Clq and tumor necrosis related factor 2 & Clqtnf2 & 497886 \\
Eukaryotic translation initiation factor 4 gamma I & Eif4gI & 497887 \\
Cyclin J-like & Ccnjl & 303050 \\
\hline
\end{tabular}

Abbreviation: PKD, polycystic kidney disease.

There was a highly significant difference in the values for the likelihood ratio statistics in the quantitative trait locus associated with the PKD traits. The likelihood ratio statistics and LOD score are interchangeably used to find an association between a phenotype and a genotype, with the aim of identifying genomic regions that harbor sequence variants which influence complex disease phenotypes. ${ }^{36}$ However, the likelihood ratio statistics technique is commonly used and is statistically convenient because its distribution is asymptotically a $\chi^{2}$ distribution. ${ }^{33}$

A Manhattan plot also confirmed the association of disease phenotypes in the LPK rats to the locus on chromosome 10. Therefore, this study has provided significant evidence that this quantitative trait locus is the only genetic region responsible for the phenotypic trait variation in LPK rats. The location of the quantitative trait locus in this genetic region has excluded the genetic loci that controlled expression of ARPKD in previously studied murine models of the disease. ${ }^{49,50}$ This clearly shows that the locus responsible for the disease is novel and different from the loci that contain Pkhd-1, the gene responsible for ARPKD in other models of the disease. This quantitative trait locus does not contain Nek8, located on rat chromosome 10 , mutation of which was associated with development of ARPKD in other models. ${ }^{51}$

The quantitative trait locus on rat chromosome 10q21q26 shares homology with human chromosomes 5q34-q35 and mouse chromosomes $11 \mathrm{C}$ and $18 \mathrm{~B}$. Human chromosome $5 \mathrm{q} 34-\mathrm{q} 35$ contains the MAT2 $\beta$ gene and mouse chromosomes $11 \mathrm{C}$ and $18 \mathrm{~B} 1$ contain breast carcinoma-amplified sequence 3 and Ras-like without CAAX2, respectively. These genes are different from $P k h d-1$, which is responsible for ARPKD in other murine models. However, the genes are important in signal transduction, cell proliferation, and cell differentiation, ${ }^{52,53}$ and their mutations were previously linked to development of cancer in different human and rat tissues. ${ }^{54-56}$ Nonetheless, there is no evidence in the present study to suggest that the ARPKD inherited in $\mathrm{LPK} / \mathrm{SsNArc}^{+/+}$ rats is a cancer of kidney tissue. The location of the quantitative trait locus on chromosome 10q21-q26, which maps to human chromosome 5q34-q35, has excluded previously the identified human locus on chromosome 6p21.1-p12 ${ }^{16}$ as a possible candidate in the development of ARPKD in LPK rats.

\section{Conclusion}

It has been established that a recessive mutation in a single gene at a quantitative trait locus region located on rat chromosome 10q21-q26 is responsible for ARPKD in LPK rats. Unlike other forms of ARPKD that result in liver-related morbidity and mortality, the ARPKD in this rat model is not associated with liver-related death. Accumulation of fluids in the cysts resulted in kidney enlargement, and with time, kidney homeostatic function deteriorated. Deterioration in kidney function resulted in an increase in systolic blood pressure, a mechanism to compensate for decreased renal perfusion. Because the quantitative trait locus that harbors the disease gene responsible for the phenotypic trait variation spans a large genetic region in chromosome 10, genetic mapping of the entire chromosome using a dense set of simple sequence repeat markers along the chromosome is underway to identify the actual quantitative trait locus and the gene involved in expression of the disease. In addition, it is recommended that expression studies be carried out to explain the reason for the phenotypic trait variation between LPK and other rat models in the development of ARPKD. Therefore, this study has created an opportunity to identify the mutated gene and the type of mutation responsible for ARPKD in LPK rats. It has also presented a possibility for more research with the aim of identifying therapeutic interventions to prevent and/or cure ARPKD.

\section{Acknowledgments}

Dora Li and Andrew Williams of Murdoch University are thanked for their assistance and technical support with this study.

\section{Disclosure}

The author reports no conflicts of interest in this work.

\section{References}

1. Martinez JR, Grantham JJ. Polycystic kidney disease: etiology, pathogenesis, and treatment. Dis Mon. 1995;41(11):693-765.

2. Grantham JJ. The etiology, pathogenesis, and treatment of autosomal dominant polycystic kidney disease: recent advances. Am J Kidney Dis. 1996;28(6):788-803. 
3. Lyons LA, Biller DS, Erdman CA, et al. Feline polycystic kidney disease mutation identified in PKD1. J Am Soc Nephrol. 2004;15(10): 2548-2555.

4. Iakoubova OA, Dushkin H, Beier DR. Genetic analysis of a quantitative trait in a mouse model of polycystic kidney disease. Am J Respir Crit Care Med. 1997;156(4 Pt 2):S72-S77.

5. Woo DD, Nguyen DK, Khatibi N, Olsen P. Genetic identification of two major modifier loci of polycystic kidney disease progression in pcy mice. J Clin Invest. 1997;100(8):1934-1940.

6. Deltas C, Papagregoriou G. Cystic diseases of the kidney: molecular biology and genetics. Arch Pathol Lab Med. 2010;134(4):569-582.

7. Bihoreau MT, Megel N, Brown JH, et al. Characterization of a major modifier locus for polycystic kidney disease (Modpkdr1) in the Han:SPRD(cy/+) rat in a region conserved with a mouse modifier locus for Alport syndrome. Hum Mol Genet. 2002;11(18):2165-2173.

8. Guay-Woodford LM, Wright CJ, Walz G, Churchill GA. Quantitative trait loci modulate renal cystic disease severity in the mouse bpk model. J Am Soc Nephrol. 2000;11(7):1253-1260.

9. Upadhya P, Churchill G, Birkenmeier EH, Barker JE, Frankel WN. Genetic modifiers of polycystic kidney disease in intersubspecific KAT2J mutants. Genomics. 1999;58(2):129-137.

10. Guay-Woodford LM. Murine models of polycystic kidney disease: molecular and therapeutic insights. Am J Physiol Renal Physiol. 2003; 285(6):F1034-F1049.

11. Bogdanova N, MarkoffA, Gerke V, McCluskey M, Horst J, Dworniczak B. Homologues to the first gene for autosomal dominant polycystic kidney disease are pseudogenes. Genomics. 2001;74(3):333-341.

12. Chittenden L, Lu X, Cacheiro NL, et al. A new mouse model for autosomal recessive polycystic kidney disease. Genomics. 2002;79(4): 499-504.

13. Mucher G, Becker J, Knapp M, et al. Fine mapping of the autosomal recessive polycystic kidney disease locus (PKHD1) and the genes MUT, RDS, CSNK2 beta, and GSTA1 at 6p21.1-p12. Genomics. 1998;48(1) 40-45.

14. Wilson PD. Mouse models of polycystic kidney disease. Curr Top Dev Biol. 2008;84:311-350.

15. Bergmann C, Senderek J, Sedlacek B, et al. Spectrum of mutations in the gene for autosomal recessive polycystic kidney disease (ARPKD/ PKHD1). J Am Soc Nephrol. 2003;14(1):76-89.

16. Onuchic LF, Mrug M, Hou X, et al. Refinement of the autosomal recessive polycystic kidney disease (PKHD1) interval and exclusion of an EF hand-containing gene as a PKHD1 candidate gene. Am J Med Genet. 2002;110(4):346-352.

17. Zhang J, Wu M, Wang S, Shah JV, Wilson PD, Zhou J. Polycystic kidney disease protein fibrocystin localizes to the mitotic spindle and regulates spindle bipolarity. Hum Mol Genet. 2010;19(17):3306-3319.

18. Onuchic LF, Furu L, Nagasawa Y, et al. PKHD1, the polycystic kidney and hepatic disease 1 gene, encodes a novel large protein containing multiple immunoglobulin-like plexin-transcription-factor domains and parallel beta-helix 1 repeats. Am J Hum Genet. 2002;70(5):1305-1317.

19. Losekoot M, Haarloo C, Ruivenkamp C, White SJ, Breuning MH, Peters DJ. Analysis of missense variants in the PKHD1-gene in patients with autosomal recessive polycystic kidney disease (ARPKD). Hum Genet. 2005;118(2):185-206.

20. Reeders ST, Breuning MH, Davies KE, et al. A highly polymorphic DNA marker linked to adult polycystic kidney disease on chromosome 16. Nature. 1985;317(6037):542-544.

21. Bastos AP, Onuchic LF. Molecular and cellular pathogenesis of autosomal dominant polycystic kidney disease. Braz J Med Biol Res. 2011; 44(7):606-617.

22. No authors listed. Autosomal dominant polycystic kidney disease. Srp Arh Celok Lek. 2008;136 Suppl 4:340-347. Serbian.

23. Wolf MT, Hildebrandt F. Nephronophthisis. Pediatr Nephrol. 2011; 26(2):181-194.

24. Hu B, He X, Li A, et al. Cystogenesis in ARPKD results from increased apoptosis in collecting duct epithelial cells of Pkhd1 mutant kidneys. Exp Cell Res. 2011;317(2):173-187.
25. Kazancioglu R, Ecder T, Altintepe L, et al. Demographic and clinical characteristics of patients with autosomal dominant polycystic kidney disease: a multicenter experience. Nephron Clin Pract. 2010;117(3): c270-c275.

26. Nagasawa Y, Matthiesen S, Onuchic LF, et al. Identification and characterization of Pkhd1, the mouse orthologue of the human ARPKD gene. J Am Soc Nephrol. 2002;13(9):2246-2258.

27. Ponticelli C, Locatelli F. Autosomal dominant polycystic kidney disease and mTOR inhibitors: the narrow road between hope and disappointment. Nephrol Dial Transplant. 2010;25(12):3809-3812.

28. Gunay-Aygun M, Font-Montgomery E, Lukose L, et al. Correlation of kidney function, volume and imaging findings, and PKHD1 mutations in 73 patients with autosomal recessive polycystic kidney disease. Clin J Am Soc Nephrol. 2010;5(6):972-984.

29. Woollard JR, Punyashtiti R, Richardson S, et al. A mouse model of autosomal recessive polycystic kidney disease with biliary duct and proximal tubule dilatation. Kidney Int. 2007;72(3):328-336.

30. Harris PC, Rossetti S. Molecular genetics of autosomal recessive polycystic kidney disease. Mol Genet Metab. 2004;81(2):75-85.

31. Lager DJ, Qian Q, Bengal RJ, Ishibashi M, Torres VE. The pck rat: a new model that resembles human autosomal dominant polycystic kidney and liver disease. Kidney Int. 2001;59(1):126-136.

32. Phillips JK, Hopwood D, Loxley RA, et al. Temporal relationship between renal cyst development, hypertension and cardiac hypertrophy in a new rat model of autosomal recessive polycystic kidney disease. Kidney Blood Press Res. 2007;30(3):129-144.

33. Manly KF, Cudmore RH Jr, Meer JM. Map Manager QTX, cross-platform software for genetic mapping. Mamm Genome. 2001;12(12):930-932.

34. Lander E, Kruglyak L. Genetic dissection of complex traits: guidelines for interpreting and reporting linkage results. Nat Genet. 1995;11(3): 241-247.

35. Abiola O, Angel JM, Avner P, et al. The nature and identification of quantitative trait loci: a community's view. Nat Rev Genet. 2003;4(11): 911-916.

36. Fallin D, Cohen A, Essioux L, et al. Genetic analysis of case/control data using estimated haplotype frequencies: application to APOE locus variation and Alzheimer's disease. Genome Res. 2001;11(1):143-151.

37. Nauta J, Goedbloed MA, Herck HV, et al. New rat model that phenotypically resembles autosomal recessive polycystic kidney disease. J Am Soc Nephrol. 2000;11(12):2272-2284.

38. Ward CJ, Hogan MC, Rossetti S, et al. The gene mutated in autosomal recessive polycystic kidney disease encodes a large, receptor-like protein. Nat Genet. 2002;30(3):259-269.

39. Guay-Woodford LM, Bryda EC, Christine B, et al. Evidence that two phenotypically distinct mouse PKD mutations, bpk and jcpk, are allelic. Kidney Int. 1996;50(4):1158-1165.

40. Fall PJ, Prisant LM. Polycystic kidney disease. J Clin Hypertens (Greenwich). 2005;7(10):617-619.

41. Gabow PA, Chapman AB, Johnson AM, et al. Renal structure and hypertension in autosomal dominant polycystic kidney disease. Kidney Int. 1990;38(6):1177-1180.

42. Chapman AB, Johnson A, Gabow PA, Schrier RW. The renin-angiotensinaldosterone system and autosomal dominant polycystic kidney disease. N Engl J Med. 1990;323(16):1091-1096.

43. Goto M, Hoxha N, Osman R, Wen J, Wells RG, Dell KM. Reninangiotensin system activation in congenital hepatic fibrosis in the PCK rat model of autosomal recessive polycystic kidney disease. $J$ Pediatr Gastroenterol Nutr. 2010;50(6):639-644.

44. Jain S, Kamat D. Evaluation of microcytic anemia. Clin Pediatr (Phila). 2009;48(1):7-13.

45. Gutierrez-Gil B, Alvarez L, de la Fuente LF, Sanchez JP, San Primitivo F, Arranz JJ. A genome scan for quantitative trait loci affecting body conformation traits in Spanish Churra dairy sheep. J Dairy Sci. 2011; 94(8):4119-4128.

46. Hao Z, Li X, Xie C, et al. Identification of functional genetic variations underlying drought tolerance in maize using SNP markers. $J$ Integr Plant Biol. 2011;53(8):641-652. 
47. Ronnegard L, Valdar W. Detecting major genetic loci controlling phenotypic variability in experimental crosses. Genetics. 2011;188(2): 435-447.

48. Uleberg E, Meuwissen TH. The complete linkage disequilibrium test: a test that points to causative mutations underlying quantitative traits. Genet Sel Evol. 2011;43:20.

49. Zerres K, Mucher G, Bachner L, et al. Mapping of the gene for autosomal recessive polycystic kidney disease (ARPKD) to chromosome 6p21-cen. Nat Genet. 1994;7(3):429-432.

50. Guay-Woodford LM, Desmond RA. Autosomal recessive polycystic kidney disease: the clinical experience in North America. Pediatrics. 2003;111(5 Pt 1):1072-1080.

51. Smith LA, Bukanov NO, Husson H, et al. Development of polycystic kidney disease in juvenile cystic kidney mice: insights into pathogenesis, ciliary abnormalities, and common features with human disease. $J \mathrm{Am}$ Soc Nephrol. 2006;17(10):2821-2831.
52. Bourne HR, Sanders DA, McCormick F. The GTPase superfamily: a conserved switch for diverse cell functions. Nature. 1990;348(6297): $125-132$.

53. Hoshino M, Yoshimori T, Nakamura S. Small GTPase proteins Rin and Rit Bind to PAR6 GTP-dependently and regulate cell transformation. J Biol Chem. 2005;280(24):22868-22874.

54. Margolis B, Skolnik EY. Activation of Ras by receptor tyrosine kinases. J Am Soc Nephrol. 1994;5(6):1288-1299.

55. Garbay C, Liu WQ, Vidal M, Roques BP. Inhibitors of Ras signal transduction as antitumor agents. Biochem Pharmacol. 2000;60(8): $1165-1169$.

56. Cowley BD Jr, Chadwick LJ, Grantham JJ, Calvet JP. Elevated proto-oncogene expression in polycystic kidneys of the C57BL/6J (cpk) mouse. J Am Soc Nephrol. 1991;1(8):1048-1053.

\section{Publish your work in this journal}

Advances in Genomics and Genetics is an international, peer reviewed, open access journal that focuses on new developments in characterizing the human and animal genome and specific gene expressions in health and disease. Particular emphasis will be given to those studies that elucidate genes, biomarkers and targets in the development of new or improved therapeutic interventions. The journal is characterized by the rapid reporting of reviews, original research, methodologies, technologies and analytics in this subject area. The manuscript management system is completely online and includes a very quick and fair peer-review system. Visit http://www.dovepress.com/ testimonials.php to read real quotes from published authors.

Submit your manuscript here: http://www.dovepress.com/advances-in-genomics-and-gene-expression-journal 